\title{
Analysis on the Chinese Painting Art Spirit in the Landscape Oil Paintings of Wu Guanzhong
}

\author{
Wenxiu Li \\ School of Art and Design \\ Huanghe Science and Technology College \\ Zhengzhou, China
}

\begin{abstract}
The achievement of landscape oil paintings of Wu Guanzhong is closely related to his reference to Chinese painting especially his application and comprehension to the Chinese painting spirit. The author tries to demonstrate the spirit by the following three aspects: spatial switching, visual cues of black and white, consciously use of writing images, artistic conception.
\end{abstract}

Keywords - landscape oil paintings; Chinese painting art spirit; black and white artistic conception

\section{INTRODUCTION}

There is no doubt that $\mathrm{Wu}$ Guanzhong is an art master with a thorough knowledge of both western and traditional Chinese. Following $\mathrm{Xu}$ Beihong and Lin Fengmian, he greatly improved the integration of eastern and western arts. He influenced both theory and form of modern Chinese arts greatly. Landscape oil painting is the key art field for $\mathrm{Wu}$ Guanzhong so its artistry should not be doubted at all. What makes the landscape oil painting valuable is not changed skills or original style but the application of Chinese elements on the basis of knowing Chinese traditional culture well. So he wrote in To the unknown "oil painting is the base of wash painting while wash painting is the skeleton of oil painting. They accompany me all life and are the two sides of art entity or two flanks". Then, what's the distinctive difference between works of $\mathrm{Wu}$ Guanzhong and that of others? First of all, the representation of $\mathrm{Wu}$ Guanzhong's works takes in the characters of western modern painting schools, that is, under the influence of valuing form, it stresses the application of color, lines, rhythm and rhyme. Then, it refers to the representation skills of Chinese painting (especially landscape painting), namely the research on imagination and reality, block surface, black and white as well as artistic conception and their application. After "the cultural revolution", he prefers to value imagery plastic and build artistic conception based on the Chinese painting in his oil landscape painting. He applies a great amount of practical experience of wash painting to oil painting with the hope of achieving Chinese painting spirits in oil painting. Does Chinese painting have spirits? Yes, it does. It is called Chinese painting because it has unique temperament, appearance, and skills. Its spirits can be analyzed from three aspects. The first is the ideological source of artistic thoughts. The Chinese painting has been influenced by Taoism, Confucianism and Buddhist deeply in its development. Taoism stresses harmonious flow beauty in form and uses the basic representation skill—black and white. In space transformation, it values keeping black with white and using white as black. Confucianism emphases on neutralization and pursues fairness and harmony, completeness and coordination in picture relation. Buddhist highlights implication and interest. It breaks pure natural aesthetic taste in building artistic conception. The next is representation characters of ink. As a symbolic traditional medium with its own traditional value, its representation form also has the evaluation system of Chinese cultural traits. The last is the artistic conception of picture. The artistic conception of Chinese painting is the relationship between human and nature, person and person. It is the common product of philosophy, literature and the author's mind. This is exactly why Chinese painting has its unique charm. Then, how the oil landscape painting works of $\mathrm{Wu}$ Guanzhong manifest the spirits of Chinese painting in depth? In author's eye, there are three respects namely visual cues of black and white and spatial switching, consciously use of ink, artistic conception.

\section{VISUAL CUES OF BLACK AND White AND SPATIAL SWITCHING}

Actually, spatial switching is the dialectical cognitive relationship of size, the actual situation and colors and expresses beauty by this relationship. The spatial switching in the paintings of $\mathrm{Wu}$ Guanzhong takes the most use of space narrative techniques in Chinese painting, that is, the application of the principle keeping black with white and using white as black and there is no white or black without the other. The principle keeping black with white comes from the Chinese classical philosophy book - "Dao De Ching". It said, "Knowing what is white and wrong, this is the model of life". It refers to keeping negative on the basic of positive and keeping soft with strong. Everything is to be simmering, which is the most important key to picture formation. Black is not the color or thick ink but the imagination of the space picture. White is also not simply blank but the breath of picture structure and organic component of the picture. The space relationship, contrast relationship and rhythm relationship of the picture give people much space to image because of "white". All in all, the application of keeping black with white adds natural quality of pictures on one hand, on the other hand, it raises visual value of "white and black" to beauty level, which highlights the effect and meaning of leaving blank. Although taking white as black is a calligraphy term, it is 
practical in the creation of Chinese painting, especially in density, actual situation, rhythm, size and distance.

Landscape oil paintings of Wu Guanzhong have close relationship with white and black. He once explained the relationship between colors and white and black like this: "colors and white and black are always fighting with each other as well as attached to each other in my painting, along with the feelings of the painter". Black and white together with Chinese traditional paintings (including landscape painting, painting of flowers and birds and figure painting) has been an isomorphism of inertia psychology in visual aesthetic experience, which can be spread into any painting field, such as watercolor painting, oil painting, wood block and wall painting. These paintings usually motivate the isomorphism of inertia psychology or give visual cues by the representation of white and black.

The painting Quadrangle Dwellings (2003) takes black and white as the main color and divides pictures into large pieces, which aims at showing black surface morphology and that of leaving blank. The two depend on each other greatly and show the narrative skills. At the same time, the fluctuation of the edge contour in the joint of black and white values the balance and coordination of defense both in black and white surface morphology, which is also the result of taking white as black. The abundant application of black and white adds the indication of visual aesthetic experience. The processing of gray in picture alleviates the conflict between black and white and enrich and coordinate the picture. The principle there is no white or black without the other has been manifested in this picture fully. First of all, the roof ridge seldom uses white but in this picture the author paints it with white randomly. It seems aimless but aims a lot actually, which has the equally satisfactory results with the white and black chickens on the blank of court. That is, finding echo point from each other to match the two following the natural effect. Therefore, the relationship between black and white in the whole picture has distinctive connotation of Chinese painting.

To Chinese painting, black and white is just the visual contrast. This kind of contrast can spread to whether the color is warm or cool, whether the object is far or near, whether structure is dense or sparse, whether the layout is open or close, whether the brush is wet or dry, whether the ink is thick or thin, whether the line is heavy or light, whether the pause is long or short and whether the paint is quick or slow. Even transition and pause contrasts to each other, which is an invisible relationship between black and white. Wu Guanzhong values the visual effect of black and white very much so that he can reflect Chinese painting spirit in oil painting step by step.

\section{CONSCIOUSLY USE OF WRITING IMAGES}

Wu Guanzhong painted Chinese painting a lot when he was young, and he wasn't keen on stylized traditional Chinese painting. But after seeing landscape paintings of four famous monk painters especially Shi Tao in Qing dynasty, he devoted himself to wash painting. Why a professional painter majoring in modern western paintings is so interested in washing painting? In Where the Soul to Combine, he said, "I like researching its essence through the words. This is also common in eastern and western aesthetic concept. I love the beauty of traditional painting and intimate a lot. I love it deeply, and love it still. I also love western painting, too. I love paintings of both east and west. Love is not just for one thing and all love is my real feelings. ......I studied abroad when I was young and I studied with hostile where I was discriminated. I was proud that the Chinese arts achievement stood in the world of arts. While, it was exactly I learned the advantages of west arts that make me realized our own features, shortage and defects". Seeing from the skills and materials, the biggest character of national paintings is ink. Wu Guanzhong's realization for this point dated back to school-days in National academy of fine arts of Hangzhou, so the application of writing images in landscape oil painting is his subconscious behavior. Actually, writing images in landscape oil painting is using materials and tools to express some interesting things. As to the representation of dots and lines, they should have performance features of brushes first, such as fluctuation and pause of lines as well as size and density of dots. Then is the images representation, such as changes of ink. Wu Guanzhong stressed the representation of ink very much and he criticized exaggeration and deprivation of pictures of inks in Ink Equals to Zero, but he didn't deny its practical function. Instead of the stylized inevitability, he affirmed contingency and artistry in representing detail objects.

Houseboat (1996), took life in Yangtze river delta as background. Black backwall and white wall body, willows reflected in the lake, straight or twist, tall or short, making a quiet and elegant Jiangnan landscape together with lakes and mountains. It is exactly connotation of Chinese landscape painting. Why are paintings of Wu Guanzhong so marvelous? The most important is expressing connotation of Yangtze River delta in oil painting by that of Chinese landscape painting, at the same time, he used black, white and grey to show the spirit of ink perfectly. Saying from skills, he painted ridge and brunches by skills of Chinese paintings, especially ridges, he painted it thick and heavy, which was totally from calligraphy. While the brunches fully expressed his sincere temperament - restrained and calm while relaxed and active. The representation of black values its layout extremely, especially the shape and divide of surface, such as size, shape, layout, form and density. Its representation is similar to that of Chinese landscape painting - from dot to line then line to plane, from close shot to mid shot then to distant view. All of these entirely reflect the spirits and soul of Chinese painting.

\section{ARTISTIC CONCEPTION}

Artistic conception is the combination of feelings and scene under certain circumstances. Because of the difference between eastern and western concepts and representation, the artistic conception is also different. For example, artistic conception in Chinese paintings is focused on vivid spirits no matter what season or where the mountain is. Zong Baihua compared western and eastern paintings in The Source and Basis of Western and Eastern Painting Skills, he said, "Chinese paintings are focused on vivid spirits, the painting style is of character and Bone method uses a pen is a way of painting, so Xie He in Jin dynasty put forth six principles for painting. That is, painting objects according to its shape and 
painting its color according to same species to intimate natural things, and the layout should be harmonious and ordered, they should take up proper scale and be well-balanced. While these are the two focus thoughts in the western aesthetic thought development.

When appreciating Wu Guanzhong's landscape oil painting, we can find that artistic conception in most of his works is native. It even expresses feelings directly. So, one result is that artistic conception on the premise of the aesthetic localization often reflects the poetic artistic conception. The other result is that the combination of with individual mind, literature and philosophy often reflects the unique oriental twitters and condition. Artistic conception on the premise of the aesthetic localization in Wu's Painting gets rid of the demand for objective authenticity in western painting on one hand, on the other hand it also gets rid of the pursuit that formal beauty is the pure visual imagery in abstract art. He advocates building artistic conception like "kite with reel", so he grasps every chance to collect first-hand materials by sketching and interview all over the country, which is greatly different from painting by imagination. In Landscape Sketch Memories, he wrote, "When painting, I make a landscape form first, then find the object of image features and finally consider its artistic conception in a specific environment". This is also his direct requirement on beauty seeking. Only a person with beautiful desire can reach reflection on the content carefully.

Lotus (2002), has strong Chinese painting charm and images in Zhang Daqian's splash-color painting. The artistic conception reflected in it is not just simple survival significance of natural object or spirit like photography, but the poetic power in the same life orbit of the man and natural object and the relationship between praise and being praised. When people praise the poetic power of natural object, they are also praised. If we have to compare the Lotus with Claude Monet's Water Lily in artistic conception, it is obvious that the Water Lily only focuses on the bare life under certain times and environment and there is no externalizing relation between people and natural object. In terms of artistic conception of abstract painting, it advocates showing the inner world and will and spirit. In for-me-solely world outlook, artistic conception is at the mercy of expressing feelings and oneself as well as one's subjective moods. In the interaction with object, everything is replaced by experienced clairvoyance. Zhu Dequn, a Chinese-American painter, said, "You are what kind of person, you paint what kind of pictures, don't be restrained by frames, just put life on canvas". Lotus of Wu Guanzhong prostrates heart on the ground, seriously listens to the voice of the nature, and builds up artistic conception in the relationship between man and natural object instead of only abstract and artistic conception.

\section{CONCLUSION}

Seeing throughout $\mathrm{Wu}$ Guanzhong's landscape paintings, we can find most of the pictures penetrate the lyrical mood and connotation of traditional Chinese painting with proficient skills and examination of eastern and western culture spirit, make its picture relations rich inspirits of new era, at the same time, it integrate different Chinese and western painting concept, technique and performance characteristics effectively.
$\mathrm{Wu}$ Guanzhong gives more the national symbols and aesthetic lyricism to landscape oil painting. He inherits painting experience and aesthetic characteristics in western industry times since the impressionist. Beside the form, it deposits the national cultural traits of thousands of years and traditional pursuit of beauty. Spirit of Chinese painting makes $\mathrm{Wu}$ Guanzhong's works more charming and elegant as a unique cultural connotation.

\section{REFERENCES}

[1] Wu Guanzhong. Wo Fu DanQing(I disappoint Painting) [M].Beijing: People's Literature Publishing House, 2004.

[2] Wu Guanzhong. Mei Chou Yuan( Beauty, Ugliness and Fate) [M].Tianjin: Baihua literature and art publishing house, 2007

[3] Wu Guanzhong. Word out of pictures • Wu Guanzhong WenJi (works collection of Wu Guanzhong) [A].Jinan: Shandong pictorial publishing house, 2004.

[4] Wu Guanzhong. Yanzi Zhibi $\bullet$ Wu Guanzhong BaiRi Tan(A hundred days of Wu Guanzhong, told by Wu Guanzhong, written by Yanzi) [M] Beijing: Oriental Press, 2009

[5] Zong Baihua. Aesthetic Stroll[M].Shanghai : Shanghai People's Publishing House, 1999. 